\title{
HIPOTIREOIDISMO NA SÍNDROME NEFRÓTICA PEDIÁTRICA
}

CATEGORIA: CLÍNICO

INSTITUIÇÃO: CENTRO UNIVERSITÁRIO SÃO CAMILO

\section{AUTORES:}

GANADJIAN, Gabriela ${ }^{1}$ - Rua Sete de Outubro, 260 - Chácara

California.gabiganadjian@gmail.com

GÓES, Leonardo ${ }^{1}$

\section{ORIENTADORA:}

DIAS, Juliana²

1 Discentes da Faculdade de Medicina do Centro

Universitário São Camilo

${ }^{2}$ Docente da Faculdade de Medicina do Centro Universitário São Camilo 


\title{
HIPOTIREOIDISMO NA SÍNDROME NEFRÓTICA PEDIÁTRICA
}

\author{
CATEGORIA: CLÍNICO
}

DESCRITORES: “Nephrotic Syndrome”;

"Hypothyroidism"; "Pediatrics" 


\section{Resumo}

Introdução: A síndrome nefrótica é classicamente caracterizada por proteinúria maciça, edema e hipoalbuminemia, decorrente de lesão glomerular, sendo uma das causas mais comuns de doença renal em crianças. A perda urinária de proteínas de ligação a hormônios contribui para várias anormalidades hormonais em pacientes com essa síndrome. O hipotireoidismo é uma complicação da síndrome nefrótica relacionada à excreção acentuada de T3, T4, T4 livre e tireoglobulina na urina. Embora os testes de função tireoidiana estejam dentro da faixa normal na maioria dos pacientes nefróticos, os valores médios para tiroxina (T4), triiodotironina (T3) e globulina ligadora de tireoide são menores do que para crianças sem a doença. Objetivo: Analisar a ocorrência de hipotireioidismo na síndrome nefrótica pediátrica. Metodologia: Trata-se de uma revisão de literatura com busca de artigos no PubMed. Foram encontrados 17 artigos com os descritores Nephrotic Syndrome and Hypothyroidism and Pediatrics. Após a exclusão de artigos que não se adequavam ao tema desse trabalho, restaram 8 artigos que foram analisados. Resultados: Estudos transversais mostram uma diminuição nas concentrações séricas de T4 e T3 em crianças nefróticas não tratadas em comparação com os mesmos pacientes em remissão e controles. Além disso, o TSH estava aumentado nesse mesmo grupo. Também foi encontrada correlação inversamente proporcional entre a proteinúria e os níveis séricos de T3, T4, T4 livre e tireoglobulina, e entre a albumina plasmática e os valores de TSH. Em relação aos diferentes subtipos histopatológicos, não foi encontrada associação entre valores de T3, T4 e TSH. Em um estudo caso-controle foi encontrada correlação positiva entre os níveis séricos de albumina e os níveis séricos de T3 na fase nefrótica, mas não em relação aos níveis de T4, T4 livre e TSH. Os níveis séricos de T3, T4 e T4 livre aumentaram e os de TSH diminuíram após remissão da doença, independentemente da terapia com levotiroxina nos pacientes com hipotireoidismo subclínico e síndrome do T3 baixo. Conclusão: Os achados sugerem que o hipotireoidismo na SN é causado, em parte, por perdas acentuadas de T4, T4 livre e T3 na urina, tendo seus valores séricos correlação negativa com a proteinúria relatada nesses pacientes. No entanto, poucos artigos foram encontrados sobre o tema, sendo necessários mais trabalhos para identificação de prevalência, curso e fatores associados à complicação. 


\section{Introdução}

A síndrome nefrótica (SN) é uma doença glomerular que geralmente afeta crianças e é caracterizada por proteinúria maciça, edema e hipoalbuminemia. A proteinúria é resultado do aumento da permeabilidade da parede capilar glomerular e subsequente diminuição da reabsorção pelas células epiteliais do túbulo proximal. ${ }^{1}$

A perda urinária de proteínas de ligação a hormônios contribui para várias anormalidades hormonais em pacientes com essa síndrome. ${ }^{2} \mathrm{O}$ hipotireoidismo é uma das complicações e está relacionado à excreção acentuada de tiroxina (T4), triiodotironina (T3), hormônio estimulante da tireoide (TSH) e globulina de ligação à tiroxina (TBG) na urina. ${ }^{1,2}$

A excreção acentudada de proteinas também danifica os túbulos renais e reduz a reabsorção de proteínas de baixo peso molecular, incluindo hormônios da tireóide livres. Uma redução na reserva de hormônio tireoidiano pode aumentar o risco de hipotireoidismo em pacientes com síndrome nefrótica. ${ }^{1,3}$

Outros fatores além da proteinúria maciça podem estar envolvidos nas alterações da função tireoidiana, dentre eles o uso prolongado de esteróides e outros imunossupressores usados no tratamento da doença renal também pode afetar a tireóide. ${ }^{1}$

A TBG, T4, T3 e TSH costumam ser normais em adultos com síndrome nefrótica, apesar das perdas urinárias dessas substâncias, e esses pacientes são considerados eutireoidianos. No entanto, em crianças com síndrome nefrótica foram encontradas baixas concentrações séricas de TBG e T4 e altas concentrações séricas de TSH, devido a maiores perdas de TBG e T4 em crianças do que em adultos. $^{4}$

Embora os testes de função tireoidiana estejam dentro da faixa normal na maioria dos pacientes nefróticos, os valores médios para tiroxina (T4), triiodotironina (T3) e globulina ligadora de tireoide são menores do que para crianças sem a doença. ${ }^{1}$

\section{Objetivo}

O objetivo do presente trabalho foi avaliar a literatura acerca da ocorrência de hipotireioidismo na síndrome nefrótica pediátrica. 


\section{Métodos}

Foi realizada uma revisão de literatura, através de estudos primários, consultando o banco de dados PubMed. Os descritores utilizados foram: "Nephrotic Syndrome" and "Hypothyroidism" and "Pediatrics". A busca resultou num total de 17 artigos.

Como foram encontrados poucos artigos sobre o tema, optou-se por analisar todo o material disponível que se adequasse ao objetivo da pesquisa. A busca resultou em um total de 8 artigos, que foram analisados.

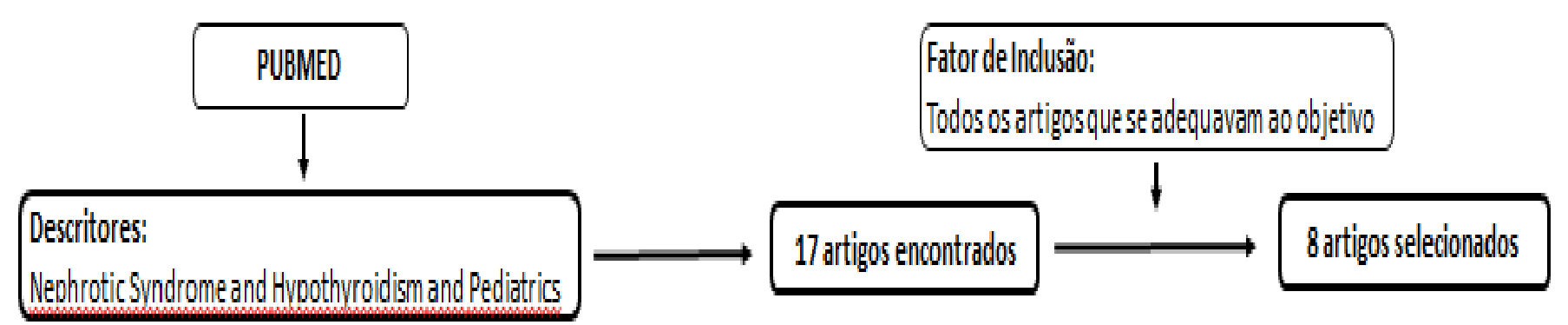

FIGURA 1: FLUXOGRAMA DE METODOLOGIA.

Os artigos contemplados foram publicados entre 1994 e 2018, sendo 3 estudos transversais, 1 caso-controle, 3 relatos de caso e 1 revisão de literatura.

\section{Resultados e Discussão}

Estudo transversal realizado por Ito e colaboradores $(1994)^{4}$ que analisou 4 meninas e 3 meninos, com idade média de 5,4 anos, com síndrome nefrótica córtico-sensível, encontrou uma correlação entre a doença renal e a ocorrência de hipotireoidismo.

A análise laboratorial mostrou diminuição nas concentrações séricas de T4, T3 e TBG em crianças nefróticas não tratadas em comparação com os mesmos pacientes em remissão e controles. Os níveis séricos de TSH estavam aumentados nas crianças nefróticas em comparação ao controle. ${ }^{4}$

Além disso, as concentrações urinárias de T4, T3, T4 livre, T3 livre e TBG nos pacientes nefróticos foram maiores do que nos pacientes em remissão ou nos controles, e a proteinúria mostrou correlação positiva com a excreção urinária de T4 $(r=0.87, P<0.01)$, T3 $(r=0.96, P<0.01)$, T4 livre $(r=0.86, P<0.01)$, TBG $(r=0.77$, 
$P<0.05)$, e negativa com os níveis séricos T4 $(r=-0.86, P<0.01)$, T3 $(r=-0.97, P$ $<0.01)$, T4 livre $(r=-0.91, P<0.01)$, e TBG $(r=-0.93, P<0.01)$. A albumina sérica apresentou correlação positiva com os níveis séricos de $T 4(r=0.86, P<0.01)$, T3 $(r=0.95, P<0.01)$, T4 livre $(r=0.84, P<0.01)$ e TBG $(r=0.86, P<0.01){ }^{4}$

Em outro estudo transversal conduzido por Kapoor et al. $(2013)^{3}$, foram avaliadas 20 crianças com síndrome nefrótica córtico-resistente, sendo 16 meninos e 4 meninas com idade média de 8,77 anos. Em nenhuma foi encontrado bócio no exame físico ou tireomegalia na ultrassonografia. Seis crianças (30\%) apresentaram hipotireoidismo subclínico: duas grau I, duas grau II e duas grau III. A média dos valores séricos de T4 nas crianças com síndrome nefrótica foi menor em comparação ao controle, e os valores de TSH naquelas crianças foram maiores.

O estudo de 30 crianças com síndrome nefrótica córtico-resistente, sendo 16 meninos e 14 meninas com idade média de 7,2 anos mostrou que 10 crianças (33.3\%) apresentaram alteração nos perfis de hormônios tireoidianos: duas hipotireoidismo evidente e oito hipotireoidismo subclínico (uma grau 1, seis grau 2 e uma grau 3$).{ }^{5}$

O TSH sérico estava aumentado nas crianças com síndrome nefrótica em comparação ao controle e houve correlação entre a proteinúria e os níveis séricos de TSH ( $r=0.329, P<0,01)$, T3 $(r=-0.301, P=0,30), T 4(r=-0.129, P=0,05)$ e entre a albumina plasmática e os níveis de TSH $(r=-0.375, \mathrm{P}<0,01){ }^{5}$

Comparando as crianças com e sem hipotireoidismo, não houve diferença em relação à idade de início e duração da $\mathrm{SN}$ e da resistência ao corticoide. Além disso, não foi encontrada associação entre valores de T3, T4 e TSH com os subgrupos histopatológicos e com a remissão da doença. ${ }^{5}$

Em estudo caso-controle conduzido em 2018 por Jung et al. ${ }^{1}, 31$ crianças com síndrome nefrótica, sendo 18 meninos e 13 meninas, com idade média de 13,7 anos foram avaliadas. Destas, $16(51,6 \%)$ apresentaram achados anormais em seus perfis de hormônios tireoidianos: seis, hipotireoidismo evidente; oito, hipotireoidismo subclínico e dois, síndrome do T3 baixo.

A relação proteína/creatinina urinária na fase nefrótica teve correlação com os níveis séricos de T3 ( $\mathrm{r}=-0.5995, P=0.0032)$, T4 ( $\mathrm{r}=-0.5797, P=0.0047)$, T4 livre $(r=-0.5513, P=0.0067)$ e TSH $(r=0.5022, P=0.0146)$. Também foi encontrada 
correlação entre os níveis séricos de albumina e os níveis séricos de T3 na fase nefrótica ( $r=0.5385, P=0.0018$ ), mas não em relação aos níveis de T4, TSH ou T4 livre. $^{1}$

Os níveis séricos de T3, T4 e T4 livre aumentaram e os de TSH diminuíram após remissão da doença, independentemente da terapia com levotiroxina nos pacientes com hipotireoidismo subclínico e síndrome do T3 baixo. ${ }^{1}$

Além dos estudos primários, 3 relatos de caso foram avaliados. Em um deles, uma criança de 15 meses com síndrome nefrótica congênita e hipotireoidismo foi avaliada. Ela apresentava cintilografia de tireoide normal e ausência de bócio. Os níveis séricos de T3 e T4 estavam suprimidos e os de TSH elevados. Após terapia com corticoide e levotiroxina oral $10 \mathrm{ug} / \mathrm{kg}$, os níveis séricos de T3 e T4 livre aumentaram, porém os níveis de TSH permaneceram altos. ${ }^{6}$

Outro relato de caso investigou uma criança com síndrome nefrótica congênita e hipotireoidismo. Ela não apresentava bócio, tinha anticorpos antitireoidianos negativos e ultrassonografia de tireoide normal. Apresentava alta necessidade de tiroxina (100-150 mcg / dia) até os 4 anos de idade. Mesmo após nefrectomia bilateral e transplante renal, o hipotireoidismo persistiu, porém com menor necessidade de tiroxina ( $62,5 \mathrm{mcg} / \mathrm{dia})$ aos 14 anos. Dessa forma não ficou claro se a deficiência de hormônios tireoidianos estava relacionada ou coincidente com a síndrome nefrótica. ${ }^{7}$

Outro caso relatado por Takakura et al. $(2015)^{8}$, uma criança de 16 anos com síndrome nefrótica córtico-resistente evoluiu com hipotireoidismo evidente após 13 dias da realização de uma tomografia computadorizada de vias urinárias com contraste iodado. Após hemodiálise e terapia com levotiroxina foram atingidos níveis normais de hormônios tireoidianos.

\section{Conclusão}

Os achados sugerem que o hipotireoidismo na SN é causado, em parte, por perdas acentuadas de T4, T4 livre, T3, TBG e TSH na urina, tendo seus valores séricos correlação negativa com a proteinúria relatada nesses pacientes.

No entanto, poucos estudos foram encontrados sobre o tema, sendo necessários mais trabalhos primários para identificação de prevalência, curso e fatores associados a essa complicação. 


\section{Referências}

1) JUNG, Sun Hee; LEE, Jeong Eun; CHUNG, Woo Yeong. Changes in the Thyroid Hormone Profiles in Children with Nephrotic Syndrome. Journal of the Korean Pediatric Society, 2018.

2) PARK, Se Jin; SHIN, Jae II. Complications of nephrotic syndrome. Korean journal of pediatrics, v. 54, n. 8, p. 322, 2011.

3) KAPOOR, Kanika et al. Subclinical non-autoimmune hypothyroidism in children with steroid resistant nephrotic syndrome. Clinical and experimental nephrology, v. 18, n. 1, p. 113-117, 2014.

4) ITO, Sachio et al. Thyroid function in children with nephrotic syndrome. Pediatric nephrology, v. 8, n. 4, p. 412-415, 1994.

5) MARIMUTHU, Vidhya; KRISHNAMURTHY, Sriram; RAJAPPA, Medha. Non-autoimmune subclinical and overt hypothyroidism in idiopathic steroid-resistant nephrotic syndrome in children. Indian pediatrics, $v$. 54, n. 11, p. 925-929, 2017.

6) MURANJAN, M. N. et al. Congenital nephrotic syndrome with clinical hypothyroidism. The Indian Journal of Pediatrics, v. 62, n. 2, p. 233235, 1995.

7) KACER, Martina et al. Congenital nephrotic syndrome and persistent hypothyroidism after bilateral nephrectomy. Journal of pediatric endocrinology \& metabolism: JPEM, v. 21, n. 6, p. 597-601, 2008.

8) TAKAKURA, Maiko et al. lodine-induced non-autoimmune hypothyroidism in a patient with steroid-resistant nephrotic syndrome. Pediatrics International, v. 57, n. 5, p. 1055-1056, 2015. 